\title{
Best Practices for NPT Transit Matching
}

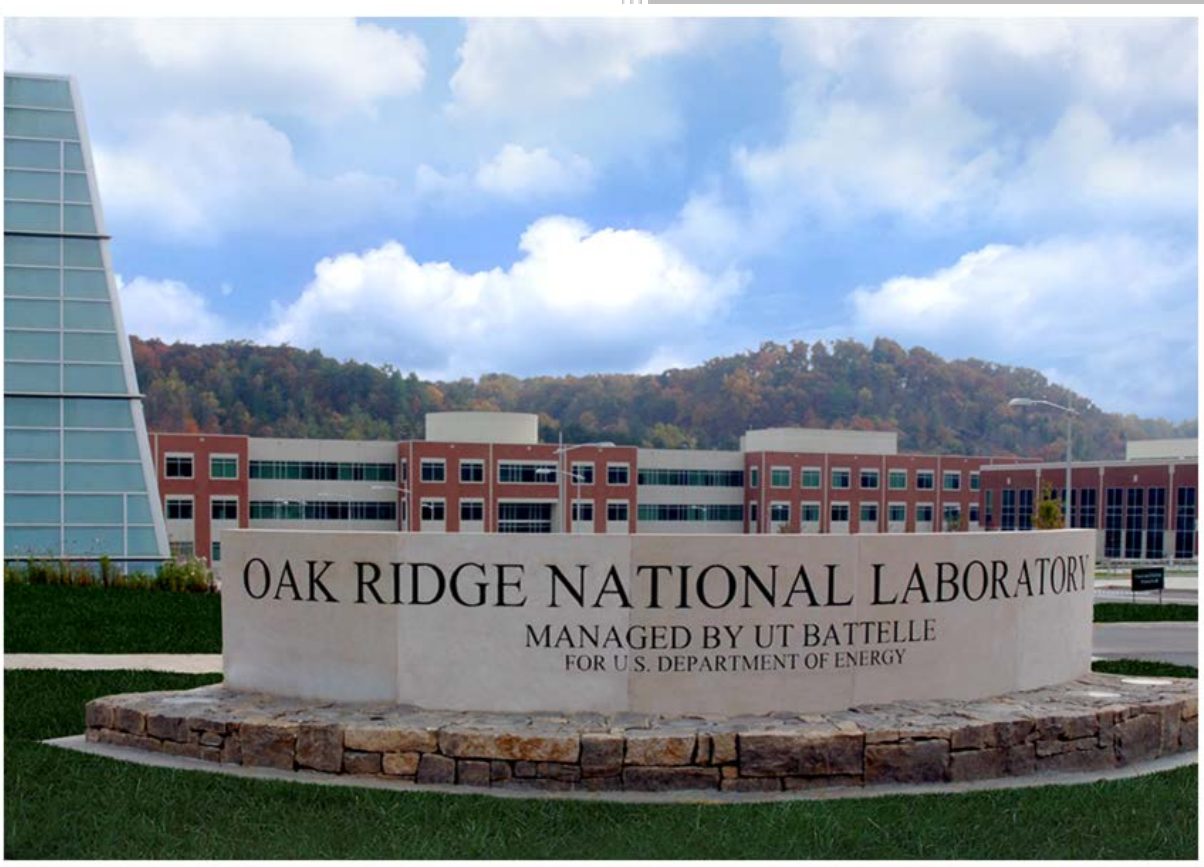

Kimberly Gilligan Catherine Snow John Oakberg Michael Whitaker

September 2016 


\title{
DOCUMENT AVAILABILITY
}

Reports produced after January 1, 1996, are generally available free via US Department of Energy (DOE) SciTech Connect.

\section{Website http://www.osti.gov/scitech/}

Reports produced before January 1, 1996, may be purchased by members of the public from the following source:

\author{
National Technical Information Service \\ 5285 Port Royal Road \\ Springfield, VA 22161 \\ Telephone 703-605-6000 (1-800-553-6847) \\ TDD 703-487-4639 \\ Fax 703-605-6900 \\ E-mail info@ntis.gov \\ Website http://www.ntis.gov/help/ordermethods.aspx
}

Reports are available to DOE employees, DOE contractors, Energy Technology Data Exchange representatives, and International Nuclear Information System representatives from the following source:

Office of Scientific and Technical Information

PO Box 62

Oak Ridge, TN 37831

Telephone 865-576-8401

Fax 865-576-5728

E-mail reports@osti.gov

Website http://www.osti.gov/contact.html

This report was prepared as an account of work sponsored by an agency of the United States Government. Neither the United States Government nor any agency thereof, nor any of their employees, makes any warranty, express or implied, or assumes any legal liability or responsibility for the accuracy, completeness, or usefulness of any information, apparatus, product, or process disclosed, or represents that its use would not infringe privately owned rights. Reference herein to any specific commercial product, process, or service by trade name, trademark, manufacturer, or otherwise, does not necessarily constitute or imply its endorsement, recommendation, or favoring by the United States Government or any agency thereof. The views and opinions of authors expressed herein do not necessarily state or reflect those of the United States Government or any agency thereof. 
Nuclear Security and Isotope Technology Division

Best Practices for NPT Transit Matching

\author{
Kimberly Gilligan \\ Catherine Snow ${ }^{1}$ \\ John Oakberg ${ }^{2}$ \\ Michael Whitaker
}

${ }^{1}$ Sno Consulting, LLC, Sandy, UT, USA

${ }^{2}$ Tetra Tech, Inc., Oak Ridge, TN, USA

Date Published: September 2016

Prepared by

OAK RIDGE NATIONAL LABORATORY

Oak Ridge, TN 37831-6283

managed by

UT-BATTELLE, LLC

for the

US DEPARTMENT OF ENERGY

under contract DE-AC05-00OR22725 



\section{CONTENTS}

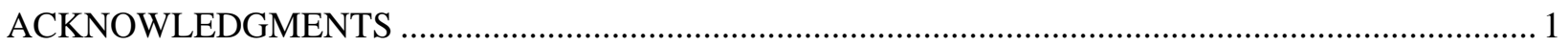

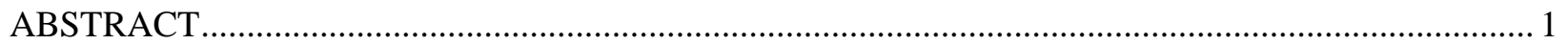

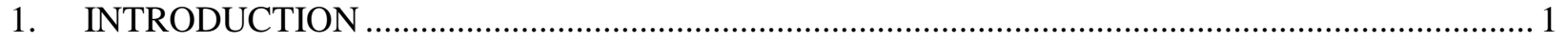

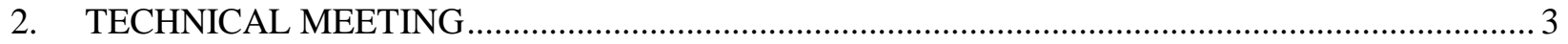

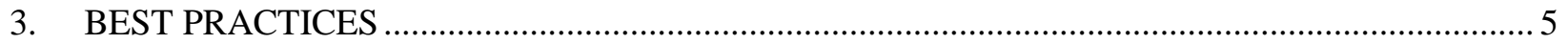

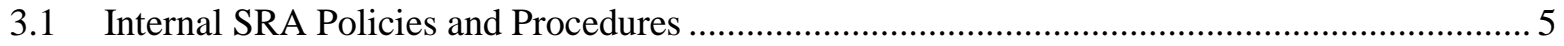

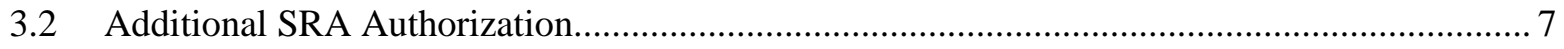

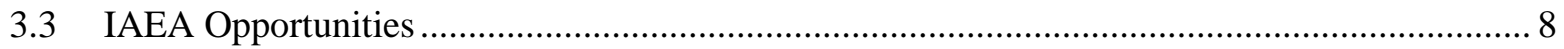

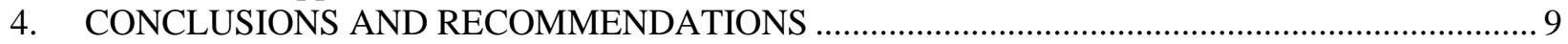

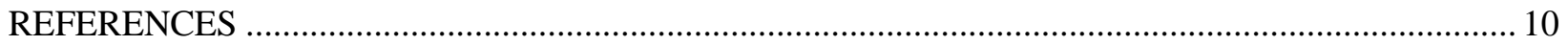

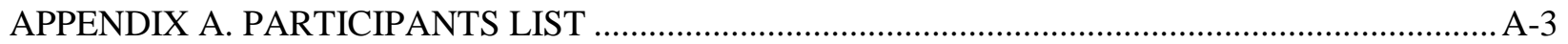

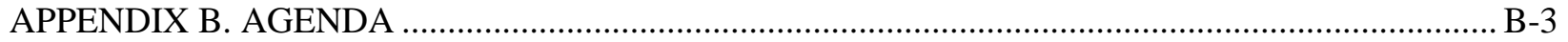




\section{ACRONYMS, ABBREVIATIONS, AND INITIALISM}

IAEA International Atomic Energy Agency

ICR Inventory Change Report

NNSA National Nuclear Security Agency

ORNL Oak Ridge National Laboratory

SGIM IAEA's Division of Information Management

SIR Safeguards Implementation Report

SRA State or Regional Authority 


\section{ACKNOWLEDGMENTS}

The authors thank the U.S. Department of Energy's NNSA Office of Nonproliferation and Arms Control (NA-24) for the support given to this transit matching project. In particular, encouragement and approval by Melissa Einwechter of NA-24 is greatly appreciated. Input and collaboration with the International Atomic Energy Agency's (IAEA's) Division of Information Management Declared Information Analysis Section was invaluable. The authors also wish to thank NNSA's Pete Dessaules, and NNSA subcontractors Brian Horn and Ed Wonder. Finally, a special thanks to the international workshop participants: Alain Rialhe and Brigitte Jonas from the IAEA; Jennifer Sample from Canada, Cedric De Walsche and Carla Teixeira from Euratom, and Yusuke Yagihashi from Japan. 


\begin{abstract}
Transit matching is the process for relating or "matching” reports of shipments and receipts submitted to the International Atomic Energy Agency (IAEA). Transit matching is a component used by the IAEA in drawing safeguards conclusions and performing investigative analysis. Transit matching is part of IAEA safeguards activities and the State evaluation process, and it is included in the annual Safeguards Implementation Report (SIR). Annually, the IAEA currently receives reports of $\sim 900,000$ nuclear material transactions, of which $\sim 500,000$ are for domestic and foreign transfers. Of these, the IAEA software can automatically match (i.e., machine match) about $95 \%$ of the domestic transfers and $25 \%$ of the foreign transfers. Given the increasing demands upon IAEA resources, it is highly desirable for the machine-matching process to match as many transfers as possible. Researchers at Oak Ridge National Laboratory (ORNL) have conducted an investigation funded by the National Nuclear Security Administration through the Next Generation Safeguards Initiative to identify opportunities to strengthen IAEA transit matching. Successful matching, and more specifically machine matching, is contingent on quality data from the reporting States. In February 2016, ORNL hosted representatives from three States, the IAEA, and Euratom to share results from past studies and to discuss the processes, policies, and procedures associated with State reporting for transit matching. Drawing on each entity's experience and knowledge, ORNL developed a best practices document to be shared with the international safeguards community to strengthen transit matching. This paper shares the recommendations that resulted from this strategic meeting and the next steps being taken to strengthen transit matching.
\end{abstract}

\title{
1. INTRODUCTION
}

Transit matching is the process for relating or "matching” reports of shipments and receipts submitted to the International Atomic Energy Agency (IAEA). Transit matching is a component used by the IAEA in drawing safeguards conclusions and performing investigative analysis. The status of transit matching is part of IAEA safeguards activities and the State evaluation process, and it is included in the Safeguards Implementation Report (SIR). Annually, the IAEA currently receives reports of $\sim 900,000$ nuclear material transactions, of which $\sim 500,000$ are for domestic and foreign transfers. Of these, the IAEA software can automatically match (i.e., machine match) about $95 \%$ of the domestic transfers and $25 \%$ of the foreign transfers. Given the increasing demands upon IAEA resources, it is highly desirable for the machine-matching process to match as many transfers as possible. Successful matching, and more specifically machine matching, is contingent on quality data from the reporting States.

To address this, the National Nuclear Security Administrations (NNSA's) Office of International Nuclear Safeguards (OINS) initiated a project on transit matching in 2013, as part of its Next Generation Safeguards Initiative (NGSI). The initial study identified challenges facing transit matching and developed recommendations for addressing them. ${ }^{1}$ Transit matching had not been

\footnotetext{
${ }^{1}$ For more information on challenges and recommendation associated with transit matching, see IAEA NPT Transit Matching: Current Methodologies and Challenges, ORNL/TM-2013/160, UT-Battelle, LLC, Oak Ridge National Laboratory, May 2013.
} 
studied extensively since a consulting group completed a study in 1984 for the IAEA. ${ }^{2}$ The report generated from the 2013 study has served to revitalize an international dialog on the subject. A summary of the 2013 study results was shared with the international nonproliferation community during the 2014 IAEA Safeguards Symposium. ${ }^{3}$ One of the activities identified in this initial research was the need for a renewed discussion with stakeholders to identify best practices that could be shared with all IAEA Member States. Therefore, a meeting was convened on Best Reporting Practices for Nuclear Material Accountancy. This technical meeting was hosted by Oak Ridge National Laboratory on February 23-24, 2016.

The meeting objective was to investigate ways to strengthen the implementation of transit matching by:

- Sharing reporting and reconciliation practices from a variety of perspectives [i.e., two Nonnuclear Weapon States (NNWSs), one Nuclear Weapon State (NWS), one regional inspectorate, and the IAEA];

- Identifying State actions that could increase machine matching;

- Discussing representative case studies;

- Spreading understanding of factors that impact the IAEA's transit matching; and

- Drafting a document to share best reporting practices with all Member States.

The Oak Ridge National Laboratory (ORNL) meeting organizers selected a small group to ensure the effective and interactive dialogues that would be critical to success. Several States were invited, as well as a regional inspectorate and the IAEA. The meeting participants comprised 10 invited representatives from the United States, Japan, Canada, Euratom, and the IAEA (Figure 1). A full list of participants is available in Appendix A.

\footnotetext{
${ }^{2}$ Nardi, Joseph, “International Transfers of Nuclear Material.” IAEA Bulletin (Winter 1986).

${ }^{3}$ Gilligan, K., Oakberg, J., and Whitaker, J. M., “Transit Matching for International Safeguards.” Paper presented at the Symposium on International Safeguards, Vienna, October 2014.
} 


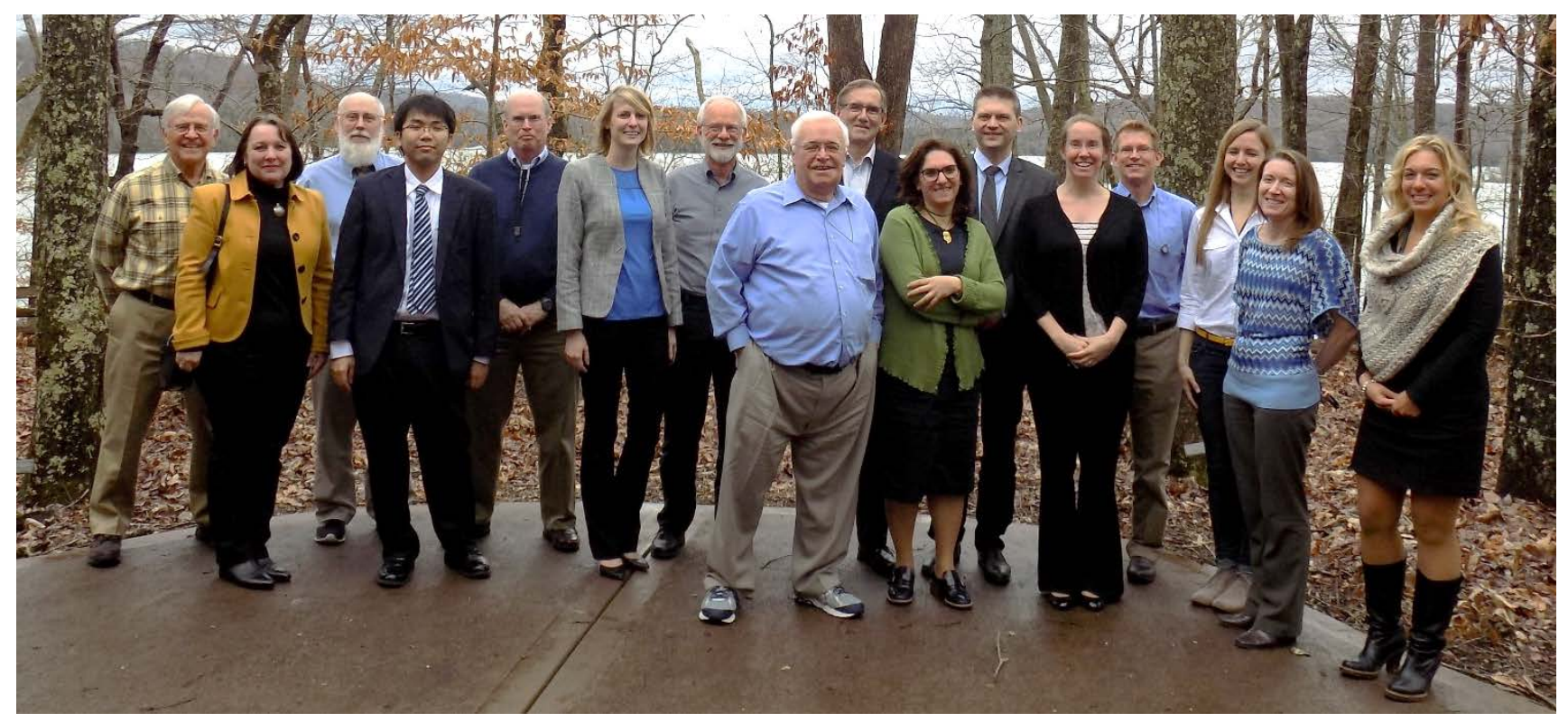

Fig. 1. Participants from the IAEA, Euratom, NNSA, Canada, Japan, and ORNL.

\section{TECHNICAL MEETING}

The meeting format valued discussion over presentations. The agenda is available in Appendix B. The meeting was kicked-off by NNSA federal program manager Melissa Einwechter introducing the project. Next, the IAEA presented an overview of its transit matching process, and it offered highlights of issues and good practices. Then each State and inspectorate gave a presentation on its processes, procedures, and policies associated with reporting based on a template that was provided prior to the meeting.

After each organization shared its best reporting practices, the participants were divided into two case study working groups (Figures 2 and 3). Each group was provided four case studies of unique nuclear material accounting reporting situations relevant to transit matching. The teams were asked to discuss each case and develop a proposed response or solution to the situation. Below are two examples of the case studies used during the meeting, using a fictional state named Neptune.

- Neptune receives a transaction from a domestic facility indicating an export and reports the transaction on an Inventory Change Report (ICR). The IAEA informs Neptune that the IAEA facility code reported for the foreign recipient is for a decommissioned facility. How should Neptune handle this?

- Neptune submitted an ICR for an export. Two weeks later, Neptune is notified that the ship had mechanical issues and had to return to Neptune without ever making the delivery. How should Neptune handle this issue? 


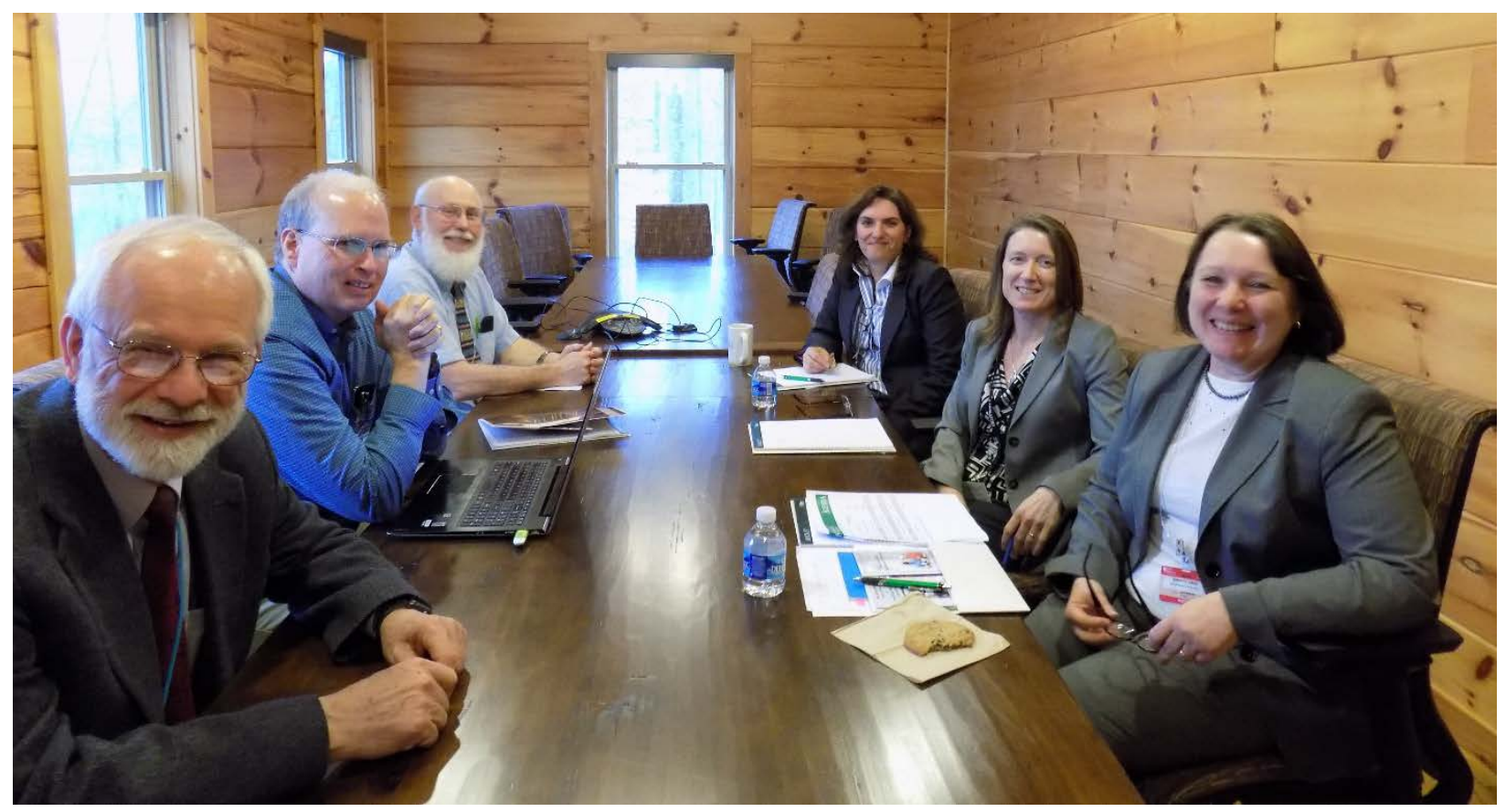

Fig. 2. Participants in Case Study Group One.

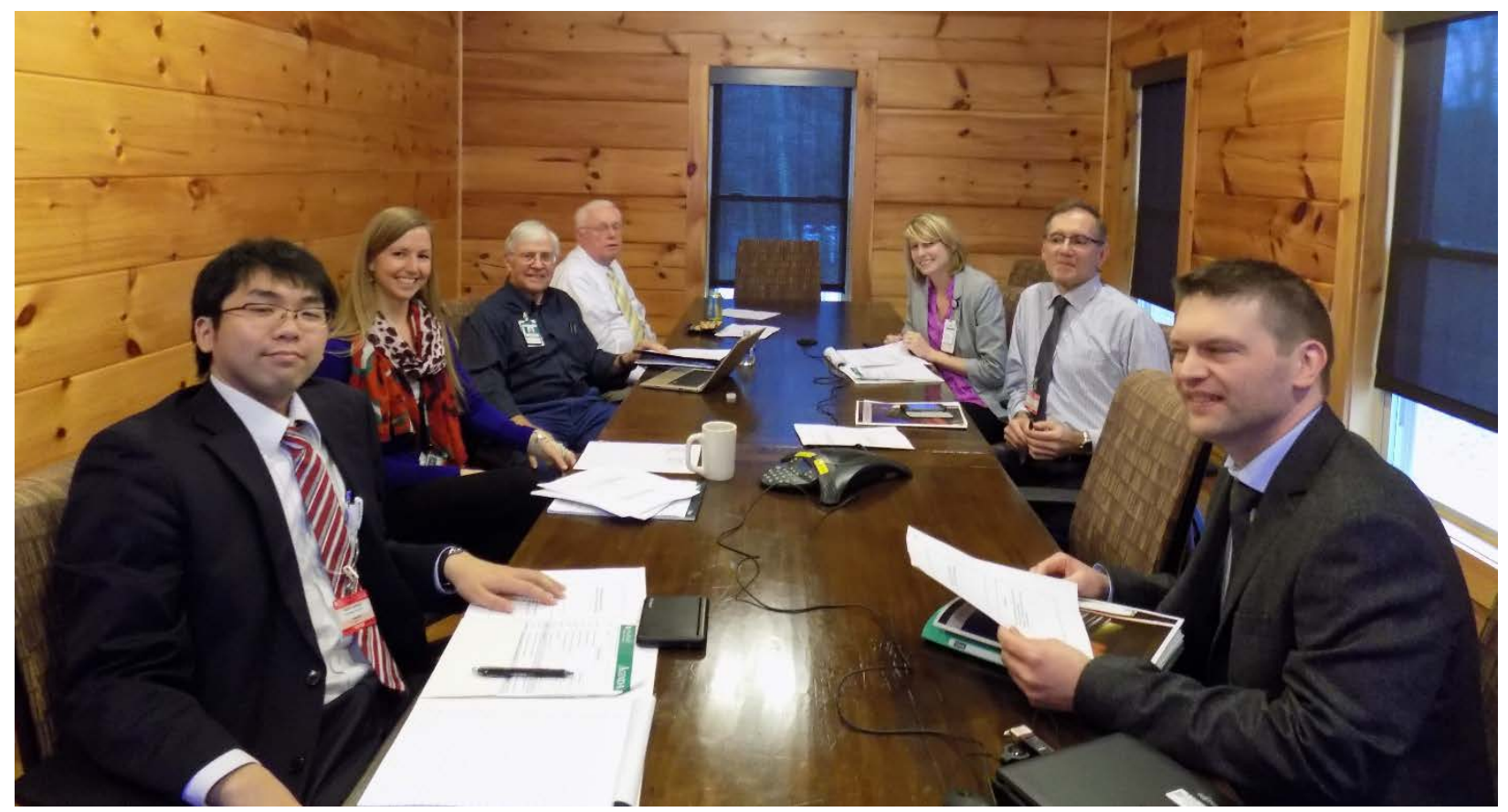

Fig. 3. Participants in Case Study Group Two. 


\section{BEST PRACTICES}

Over the two days of discussion, presentations, and case studies, a range of best practices were identified. Some best practices can be implemented with minimum burden on a State, while other best practices may require changes within the domestic regulatory framework. For this paper, these best practices are divided into three categories of implementation:

1. Practices that could be implemented now within a State or Regional Authority (SRA) responsible for safeguards implementation.

2. Practices that may require additional SRA authorization prior to implementation.

3. Practices that could be implemented by the IAEA.

\subsection{INTERNAL SRA POLICIES AND PROCEDURES}

There are several practices States can implement in their reporting policies and procedures that are unlikely to require changes to existing legal authority. Receipts must be reported using the shipper-declared values. Using the batch name and material quantities used by the shipper in the corresponding receipt report is a significant advantage to transit matching (with corrections being submitted afterwards). Operators should be aware of the IAEA's need to match transfers. The shipper should provide all necessary information to the receiver to allow for timely reporting of the receipt. Reporting should be performed in a timely fashion and with a high-level of quality to minimize transit matching issues at the IAEA. It stands to reason that reports should also reflect the physical reality and that appropriate checks should be made upon receipt.

An SRA responsible for safeguards implementation must decide that timely reporting its ICRs and resolving open, IAEA identified, transit matches is a priority. It should not be viewed as acceptable that unresolved transit matches remain open for months, years, or even decades. Rather, an SRA should strive to resolve the unmatched transfers listed in the Quarterly Import Communications and the Semi-Annual Statements as soon as possible and provide a response to the IAEA. The longer a transfer remains open, the harder it is to resolve. The reconciliation process can be strengthened by efficient communications. One way to achieve this is by establishing a clear point of contact within the SRA who will be responsible for fielding all inquiries regarding transit matching issues. It may be necessary to establish defined roles for agencies within the State System of Accounting for and Control of Nuclear Material and select one to take the lead for communication with the IAEA on transit matching issues.

Investing time and resources in training practitioners is a key way SRAs can designate transit matching as an operational priority. Training on the domestic software and the reporting metrics should be offered at least once per year for those involved in the reporting process. After a certain level of expertise is reached, a practitioner can transition to being a trainer and resource for those new to reporting. This should include offering the exchange of ideas, best practices and reporting knowledge among those contributing to reporting. In some countries, providing a certificate of completion for those completing the training with a high score has proven to be an enticing addition to encouraging the support of both management and the practitioners. Improving the abilities of the reporting personnel will directly benefit the quality of the reports which the IAEA receives. 
Each State should establish a clear contact point for transit matching issues. This can be achieved by establishing a unique email address to receive and respond to IAEA transit matching issues. This generic email address (e.g, IAEAtransitmatching@MemberState.gov) could then be linked to the appropriate safeguards officer(s) accounts so that as responsibility for reporting to the IAEA and resolving open matches is transferred, the email address stays the same. This address should be shared with the IAEA as the future point of contact. The address should also be added to the Member States' contact information in the Transit Matching National Authority List for States/Euratom Reporting to the IAEA that the IAEA maintains and provides to all Member States. This will ease the communication for the reconciliation process for unmatched transfers as well.

Clear communication between SRAs and State nuclear facilities is a key to quickly resolve transit matching questions and issues identified by the IAEA. SRAs should maintain open lines of communication with facility operators so that transit matching issues can be addressed and resolved quickly and efficiently. This will also speed the reconciliation process should the IAEA notify a State of any open transit matches (via the Quarterly Import Communication or the SemiAnnual Statement).

Face-to-face meetings can be helpful in resolving open issues. If possible, SRAs should meet with their reporting nuclear facilities once a year, or as necessary. This would provide an opportunity for SRAs to stress the importance of quality reporting by facilities to increase the quality and timeliness of State reporting. Prompt and appropriate actions are also important to solving open issues. An SRA should offer regular training to reporting facility personnel, and efforts should be made to recognize trainees for their accomplishments.

It is not just domestically that SRAs can benefit from face-to-face time. If necessary, the SRA should try to meet with the IAEA's Division of Information Management (SGIM). This may be accomplished by video- or teleconference as well. This meeting provides the SRA with an opportunity to exchange ideas with SGIM and better understand if specific issues exist in their reporting and how issues can be addressed. It also may come to light that there are generic recurring reporting issues that can be addressed to improve overall State reporting for transit matching. This is a time to discuss any unmatched transfers that have remained open through more than one Import Communication or Semi-Annual Statement. These meetings will help to build a relationship with SGIM/ISD's staff which can help facilitate the reconciliation process. Such meetings could also be a good platform to discuss any other nuclear material accounting and reporting issues.

Finally, an SRA should consider communicating directly with the SRAs of its key trading partner States. Knowing who can be contacted for transit matching issues involving other States can be invaluable facing difficulties to resolve open matches in the Quarterly Import Communications and the Semi-Annual Statements. It may be that the SRAs share similar challenges and can share their own lessons learned with each other. 
It is important to remember that receipts should be reported using the shipper-declared weights. If available, using the batch name of the shipper in the corresponding receipt report is also a significant advantage to transit matching.

\subsection{ADDITIONAL SRA AUTHORIZATION}

To implement some best practices, an SRA's domestic legal authority may need to be redefined or expanded. Performing systematic quality checks and verifications at the SRA level, including transit matching on domestic transfers, will reduce the number of transit matching open issues identified by the IAEA. An SRA should make every effort to transition fully to an electronic reporting system. Well-designed software will greatly improve the success of automatic transit matching. Specifically, error reports or warnings can help efficiently and effectively identify and resolve reporting issues, including unmatched domestic transfers prior to submission to the IAEA. Quality checks should be performed before reports are communicated to SGIM. Appropriate follow-up of any feedback provided by the SGIM also helps to achieve better quality reports and possibly reduce the number of transit matching issues. A good software system can also aid SRAs in more timely submissions as opposed to hard copy submissions.

Domestically, facilities may use different sets of material description codes, which may affect transit matching within a State. Therefore, it is a good practice to have a single set of codes used in the State accounting system. The reporting section of the Subsidiary Arrangements (i.e., Code 10) defines material description codes for reporting to the IAEA, and it is a good practice to also use equivalent codes at the facility level to simplify facility reporting actions through the use of only one set of codes at a facility. All reports to the IAEA must use the codes defined in the applicable Subsidiary Arrangements, using Fixed or Labelled formatting, depending on the Subsidiary Arrangements.

As mentioned previously, it is recommended to develop direct communication with key trading partners. In support of this recommendation, SRAs could explore bilateral agreements with provisions of advance notifications and confirmation of receipts on a timely basis. By formalizing the international communication chain, facilities and SRAs could keep each other abreast of their reporting actions to the IAEA. This would yield more cohesive reporting and increase the ability to reconcile transfers.

It would be particularly useful for NWSs voluntarily reporting under INFCIRC/207 to establish a single point of contact for all reports to the IAEA. A number of unmatched imports and exports at the IAEA are due to variants in NWS's application of the voluntary reporting. Shippers may voluntarily decide to report a transfer while the receiver does not. Further, not all Code 10 data elements are reported because they are not required under INFCIRC/207. The end result is a transfer which the IAEA cannot automatically match and that must instead be manually evaluated by the IAEA staff. By establishing a clear line of communication through a bilateral agreement, a secure IAEA portal or even a generic email address, NWSs in particular could preemptively verify and confirm which transfers they will voluntarily report. 


\subsection{IAEA OPPORTUNITIES}

The represented SRAs identified a few steps which the IAEA might implement to improve their ability to improve transit matching reporting. One recommendation is to supply States with a better definition of what constitutes a good report. In reaching this definition, States would like to receive more complete detailed quarterly reports back from the IAEA (e.g., Import Communications and Semi-Annual Statements). It would be beneficial for SRAs to receive more detailed reports outlining in particular what is the nature/type of the transit matching issue to determine more easily what aspects of the report are ineffective for the IAEA transit matching process. It would also help the SRAs if the IAEA returned quarterly reports including the same number of data sets which the SRA originally submitted. Providing personalized responses may require an increase in efforts by the IAEA staff for a few months. However, the added effort will allow States to optimize their reporting processes, thus reducing manual matching efforts of IAEA staff in the future.

Enhancement of IAEA software design and capabilities could also be a valuable assets. Welldesigned software is a key factor to maintaining high performance in the treatment of complex information. This does not only concern automatic transit matching but also manual transit matching tasks that may benefit in performance with more efficient tools.

Increasing communication between the SRAs and IAEA could be facilitated by the development of a web portal. A portal would provide a venue for direct and secure communication with IAEA staff and expedite the report feedback process. A conduit for State-to-State communication would provide SRAs the opportunity to communicate securely with each other and more easily resolve unmatched transits before or after reporting to the IAEA. The portal could include documents and references to aid States in submitting good reports. A section for frequently asked questions on the model Code 10, for example, would be especially helpful to newcomer States and those working to improve their reporting procedures.

SRAs should work to improve their practitioners' knowledge and understanding of transit matching and make reporting a priority. Those staff working in reporting should have access to the reporting section of their State's Subsidiary Arrangements. Some SRAs may rely on training offered by the IAEA and/or Member State support programs, which are not going to offer a State's exact reporting section within their Subsidiary Arrangements.

To help in this pursuit, the IAEA should look in to producing a version of Code 10 to be made available for regional and international training purposes. The current "model” Code 10 reporting document is not conducive to maintaining a continuity of knowledge as more explanation and information could be provided for the labels. Creating a more detailed userfriendly version of Code 10 would be useful to ensure that training can be offered to SRAs and facilities in a regional and international setting where a State specific Code 10 may not be appropriate.

Looking to the future, the participating States noted items for improving transit matching at the IAEA level. An increase in the number of Facility Attachments signed by the IAEA would also improve international matching. The more States and facilities operating under the same 
reporting guidelines and standards, the more likely it is that matches will be able to be matched automatically.

Finally, including transit matching statistics in the annual SIR would raise attention to the number of unmatched transfers. Reporting this may require additional support from IAEA staff, but it has the potential to greatly increase the importance of transit matching at a State level. Before taking this step the IAEA would need to further refine the requirements of what should be included in transit matching statistics in an SIR, and reviews its ability to handle manual matches. Reporting unmatched transfers by country would call attention to the current status performance and would encourage countries to make it a national priority to resolve unmatched transfers, thus improving reporting and reducing the overall number of unmatched transits.

\section{CONCLUSIONS AND RECOMMENDATIONS}

The participants appreciated the opportunity to meet their counterparts from other SRAs and discuss transit matching ideas with IAEA's SGIM. It is recommended that the delegates reconvene in two years to assess their progress in implementing the Best Practices outlined in this document. Two years should be sufficient time for the SRAs to successfully implement a number of improvements and report back on their success. Additionally, subsequent meetings could be organized to bring together States with differing reporting standards to examine their practices and implement the best practices for improved reporting. Whichever thresholds are established, regular meetings should continue to ensure that the knowledge of best reporting practices is not lost but only improved.

Finally, INFCIRC/207 should be closely examined. INFCIRC/207 is used for NWS import/export reporting of transfers with NNWSs. The existing document leaves much room for individual implementation, which tends to complicate the transit matching process. Potentially revising the thresholds would provide a more solid framework, reducing the number of unmatched transfers between NWSs. Careful attention should be paid to continue to encourage voluntary reporting of the NWSs, while providing more specific guidelines for how to best report their transactions. Furthermore, enhanced communication between NWSs on their reporting practices could be a key next step in reducing the number of open matches in a given year.

In conclusion, it is not primarily an issue of reporting timeliness but of accurate reporting that is currently delaying the IAEA's transit matching function. SRA staff who prepare reports to the IAEA should be well trained on the State's software and reporting format with a clear line of communication between nuclear facilities and SRAs. The communication should extend internationally with open lines of information exchange between States. It is expected that the implementation and application of these practices at the State level will improve nuclear material reporting to the IAEA, increase the efficiency of automatic machine matching by the IAEA and reduce the number of transfers which must be evaluated manually by the IAEA and the SRA's staff. 


\section{REFERENCES}

[1] The Structure and Content of Agreements between the Agency and States Required in Connection with the Treaty on the Non-Proliferation of Nuclear Weapons [INFCIRC/153 (Corrected)].

[2] Notification to the Agency of Exports and Imports of Nuclear Material (INFCIRC/207), International Atomic Energy Agency.

[3] Nardi, Joseph, "International Transfers of Nuclear Material.” IAEA Bulletin (Winter 1986).

[4] IAEA NPT Transit Matching: Current Methodologies and Challenges, ORNL/TM-2013/160, UT-Battelle, LLC, Oak Ridge National Laboratory (May 2013).

[5] Gilligan, K., Oakberg, J., and Whitaker, J. M., "Transit Matching for International Safeguards.” Paper presented at the Symposium on International Safeguards, Vienna, October 2014. 
APPENDIX A. PARTICIPANTS LIST 



\section{PARTICIPANTS LIST}

Alain Rialhe, International Atomic Energy Agency

Brigitte Jonas, International Atomic Energy Agency

Jennifer Sample, Canada

Cedric De Walsche, Euratom

Carla Teixeira, Euratom

Yusuke Yagihashi, Japan, Nuclear Material Control Center

Pete Dessaules, United States, National Nuclear Security Administration

Brian Horn, United States, Contractor to National Nuclear Security Administration

Melissa Einwechter, US, National Nuclear Security Administration

Ed Wonder, US, Contractor to National Nuclear Security Administration 


\section{APPENDIX B. AGENDA}





\begin{tabular}{|c|c|c|}
\hline TIME & Event & \\
\hline \multicolumn{3}{|c|}{23 February 2016} \\
\hline 8:30-9am & Distribution of visitor badges & \\
\hline 9:00-9:10 & Welcome and Safety Brief & Michael Whitaker \\
\hline 9:10-9:20 & Welcome and NGSI Overview & Melissa Einwechter \\
\hline $9: 20-9: 30$ & Meeting Objectives and Agenda Overview & Kim Gilligan \\
\hline $9: 30-9: 40$ & Welcome and Agency Objectives & Alain Rialhe \\
\hline 9:40-10:00 & Introductions & All \\
\hline $10: 00-10: 20$ & Transit Matching by the IAEA & Alain Rialhe \\
\hline 10:20-10:35 & COFFEE BREAK & \\
\hline 10:35-11:15 & Participant Presentations on State Reporting & $\begin{array}{l}\text { Pete Dessaules and Yusuke } \\
\text { Yagihashi }\end{array}$ \\
\hline $11: 15-12: 30$ & Exercise: Case Studies for Reporting Situations & Katy Snow and John Oakberg \\
\hline $12: 30-13: 30$ & LUNCH & \\
\hline $13: 30-14: 00$ & Participant Presentations on State Reporting & $\begin{array}{l}\text { Jennifer Sample, Carla Teixeira, } \\
\text { and Cedric De Walsche }\end{array}$ \\
\hline $14: 00-15: 00$ & Review Case Studies & Kim Gilligan \\
\hline $15: 00-15: 15$ & COFFEE BREAK & \\
\hline $15: 15-17: 00$ & Discussion on Best Practices & Bill Hopwood \\
\hline
\end{tabular}




\begin{tabular}{|c|c|c|}
\hline TIME & Event & \\
\hline \multicolumn{3}{|c|}{24 February 2016} \\
\hline 9:00-9:10 & Review of Key Discussion Points & Kim Gilligan \\
\hline 9:10-9:30 & Overview of ISD Beyond Transit Matching & Alain Rialhe \\
\hline $9: 30-10: 30$ & Continue Discussion on Best Practices & Bill Hopwood \\
\hline 10:30-10:45 & COFFEE BREAK & \\
\hline $10: 45-12: 00$ & Continue Discussion on Best Practices and Draft Outline & Katy Snow \\
\hline $12: 00-13: 00$ & LUNCH and Continue Discussion on Best Practices & \\
\hline 13:00-14:30 & Opportunities to increase machine matching & Ed Wonder \\
\hline $14: 30-14: 45$ & COFFEE BREAK & \\
\hline $14: 45-17: 00$ & Wrap-up and Next Steps & Kim Gilligan \\
\hline
\end{tabular}

Evening Activity: No Host Dinner at 18:30 at Cru Bistro in Turkey Creek 
